\title{
Déficit de l'activité du transporteur de glucose Glut-2 chez la souris et chez l'homme
}

Il existe au moins 6 isoformes de transporteurs de glucose plus ou moins spécialisées et dont la synthèse varie selon les tissus. Le transporteur Glut-2 est celui dont l'affinité pour le glucose est la plus faible mais dont la capacité de transport est la plus grande. Ce transporteur est présent à la membrane de toutes les cellules sécrétant du glucose dans la circulation sanguine: épithélium intestinal, tubule rénal proximal, hépatocytes. En outre, Glut-2 est l'isoforme qui assure le transport de glucose dans les cellules $\beta$ des îlots de Langerhans, et est ainsi impliqué dans le contrôle de la sécrétion de l'insuline et de la transcription de son gène [1]. En novembre 1997, la revue Nature Genetics a décrit les phénotypes associés à des déficits complets en transporteur Glut-2, chez la souris et chez l'homme. Marie-Thérèse Guillam et al. du laboratoire de Bernard Thorens (Lausanne, Suisse) ont réalisé la recombinaison homologue invalidant les deux allèles du gène Glut-2 chez la souris. Les animaux naissent sans malformation, mais présentent d'importants troubles métaboliques. Il existe une hyperglycémie modérée, avec trouble de l'insulino-sécrétion et glycosurie massive. Cependant, l'absorption du glucose par l'intestin semble normale. La survie des animaux peut être prolongée par traitement insulinique, démontrant l'intervention du diabète dans les anomalies métaboliques des souris Glut-2-1- [2]. L'observation des animaux pose plusieurs questions non résolues. Tout d'abord, l'absorption intestinale normale du glucose sug- gère que, au niveau de la face basolatérale des entérocytes, le transporteur Glut-2 peut être remplacé par une autre isoforme, non encore caractérisée. Cela doit être également vrai au niveau des cellules $\beta$ du pancréas endocrine et des hépatocytes puisque la réponse insulinique au glucose, quoique anormale, n'est pas complètement supprimée et que les hépatocytes produisent du glucose qui est sécrété dans la circulation. En revanche, la très importante glycosurie entrainant une déshydratation et une cachexie est tout à fait cohérente avec le rôle de Glut-2 dans la sécrétion sanguine du glucose réabsorbé à partir de l'urine.

Chez l'homme, le rôle du transporteur Glut-2 dans les cellules $\beta$ langerhansiennes semble être minime, ce qui est en accord avec la symptomatologie de malades atteints du syndrome de Fanconi-Bickel. Ce syndrome est caractérisé par une tubulopathie avec glycogénose hépato-rénale. De plus, l'absorption du glucose et du galactose est anormale. René Santer et al. (Kiel, Allemagne et Zurich, Suisse) [3] montrent que les sujets atteints de cette maladie autosomique récessive rare sont porteurs de mutations inactivatrices touchant les deux allèles du gène GLUT-2. L'absence de diabète est ici bien en accord avec l'utilisation par les cellules $\beta$ langerhansiennes humaines d'un autre transporteur que Glut-2, principalement Glut-1 [4]. Le rôle fondamental du transporteur Glut-2 dans la sécrétion sanguine du glucose issu de l'absorp- tion intestinale, de la réabsorption urinaire ou de la gluconéogenèse, explique aisément la totalité des signes de cette maladie. En résumé, le transporteur de glucose Glut-2 apparaît jouer deux rôle essentiels, d'importances relatives variables chez l'homme et la souris. Chez l'homme, Glut-2 apparaît avant tout comme un transporteur indispensable à la fonction des cellules ayant à sécréter du glucose dans la circulation sanguine, et son déficit entraîne donc une glycogénose, le glucose non sécrété étant détourné vers l'accumulation de glycogène. Chez la souris, outre ce rôle $[2,5]$, Glut-2 est également l'isoforme permettant au glucose d'entrer dans les cellules insulinosécrétrices, et est donc impliqué dans la réponse insulinique au glucose.

A.K.

1. Guerre-Millo M. Les transporteurs d'hexoses. Med Sci 1995; 11: 1111-9.

2. Guillam MT, Hümmler E, Schaerer E, Wu JY, Birnbaum MJ, Beermann F, Schmidt A, Dériaz N, Thorens B. Early diabetes and abnormal postnatal pancreatic islet development in mice lacking Glut-2. Nat Genet 1997; 17: 327-30.

3. Santer R, Schneppenheim R, Dombrowski A, Götze H, Steinmann B, Schaub J. Mutations in GLUT2, the gene for the liver-type glucose transporter, in patients with Fanconi-Bickel syndrome. Nat Genet 1997; 17: 324-6.

4. De Vos A, Heimberg H, Quartier E, Huypens P, Bouwens L, Pipeleers D, Schuit F. Human and rat $\beta$-cells differ in glucose transporter but not in glucokinase gene expression. J Clin Invest 1995; 96 : 89-95.

5. Antoine B, Lefrançois-Martinez AM, Le Guillou G, Leturque A, Vandewalle A, Kahn A. Role of Glut 2 glucose transporter in the response of the L-type pyruvate kinase gene to glucose in liverderived cells. J Biol Chem 1997; 272: 17937-43. 